\title{
METHODS OF STUDY OF THE LOAD DEGREE OF EQUIPMENT AND CONE DRILL BIT BEARINGS
}

\section{. . яльченков}

V. A. Pialchenkov

юменский госуд рственный нефтег зовый университет, г.юмень

лючевые слов : бурение; долото; ш рошк; опор ; н грузк

Key words: drilling; drill bit; cone bearing; the load

опросу изучения основных 3 кономерностей силового вз имодействия с 3 боем вооружения ш рошечных долот с целью определения кинем тических и силовых х p ктеристик р боты ш рошечных долот посвящено зн чительное число н литических и эксперимент льных исследов ний. ольшинство н литических методов связ но с изучением кинем тических х р ктеристик долот .

p бот $\mathrm{x}[1,2,3]$ и ряде других р ссм трив ются з кономерности движения ш рошек по з бою, предл г ются н литические з висимости для определения положения мгновенных осей вр щения ш рошки, тр екторий движения точек ш рошки и других х р ктеристик. большинстве р бот ш рошк $\mathrm{p}$ ссм трив ется к к гл дкий к ток, перек тыв ющийся по недеформируемому з бою.

ксперимент льные исследов ния $[4,5]$ пок 3 ли, что з кономерности движения зубч тых ш рошек по ре льному з бою отлич ются от результ тов, полученных н 
основе принятых моделей. то объясняется весьм сложным х р ктером ре льного Вз имодействия долот с $з$ боем.

р боте [6] предл г ется кинем тическ я модель ш рошечного долот, учитыв ющ я внедрение зубков в породу. дн ко эт методик , к к и другие, не учитыв ет ре льный х p ктер p спределения ре кции з боя вдоль обр зующей ш рошки. приорно приним ется либо $\mathrm{p}$ вномерное $\mathrm{p}$ спределение, либо изменяющееся по тр пецеид льному или п р болическому з кону с м ксимумом н периферийном венце. ри н литическом р ссмотрении процесс к чения гл дкой ш рошки с прерывистой обр зующей по деформируемому з бою [7] дел ется вывод о том, что н иболее н груженными являются периферийные венцы. ри этом предпол г ется, что деформ ция з боя подчиняется з кономерностям вязко-пл стического течения веществ и нер вномерность р спределения н грузки связ н с уменьшением скорости деформ ции при уд лении от центр з боя скв жины.

p боте [8] предл г ется метод p счет величины усилий, действующих н к ждую ш рошку для в ри нтов ст тического вз имодействия ш рошек с з боем. меняя долото стержневой системой (рис. 1) и р ссм трив я условия р вновесия этой системы, втор приходит к выводу, что н ибольшую осевую н грузку восприним ет ш рошк , опир ющ яся н вершинный венец. дн ко достоверность результ тов вызыв ет сомнения, т к к к з мен долот стержневой системой чрезмерно упрощ ет р счетную схему и не является опр вд нной.

ис. 1. счетн я схем копределению осевых усилий

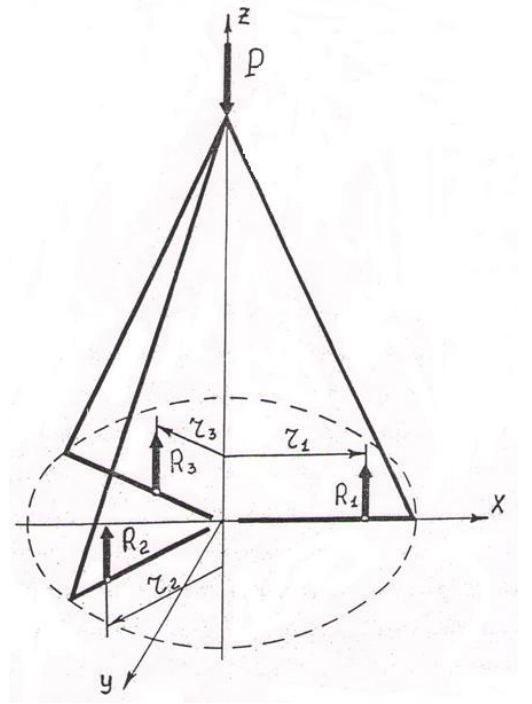

етоды н литического определения усилий, действующих н подшипники опоры ш рошечного долот , предл г ются в р бот х $[9,10]$. них предпол г ется, что осев я н грузк р спределен р вномерно между всеми ш рошк ми, ре кция з боя пропорцион льн ширине зубков. 3 условий р вновесия ш рошки и л пы, т кже дополнительных условий деформ ции определяются искомые усилия. ри этом если в р боте [9] учитыв ются деформ ции ц пфы и тел ш рошки, конт ктными деформ циями и 3 зор ми в подшипник х пренебрег ют, то в р боте [10], н оборот, учтены лишь конт ктные деформ ции и з зоры в подшипник х. результ те вторы приходят к ди метр льно противоположным вывод м. о д нным ст тьи [9], ш риковый з мковый подшипник восприним ет с мую большую р ди льную н грузку, по д нным, предст вленным в другой р боте [10] н грузк, действующ я н этот подшипник, миним льн .

н чительный интерес предст вляют результ ты комплексных теоретических и эксперимент льных исследов ний н груженности элементов ш рошечного долот, предст вленных в р бот х $[11,12,13]$. результ те теоретических исследов ний получены н литические з висимости для определения сил, действующих н ш рошку со 
стороны р зруш емой породы. дн ко в полученные з висимости входят коэффициенты, которые необходимо определять эксперимент льно. редложен метод р скрытия ст тической неопределимости подшипникового узл, позволяющий уст новить 3 висимость р спределения усилий по элемент м подшипникового узл от величины сил, действующих н ш рошку, и геометрических п р метров опорного узл . ля эксперимент льных исследов ний н грузок, действующих н ш рошку, было использов но устройство, p зр бот нное во [14]. p боте [11] предложен т кже функция цели для оптимиз ции геометрии ш рошечного долот н основе $\mathrm{p}$ зр бот нных критериев эффективности и износостойкости вооружения. олученные н литические 3 висимости дост точно сложны и для решения требуют использов ния численных методов.

етод н литического определения ре кций в подшипник х опоры ш рошечного долот предложен в р боте [15]. к честве модели р ссмотрен ш рошк, уст новленн я н ц пфе н подшипник х к чения и н груженн я осевой силой , приложенной н р сстоянии $R$ от оси долот (рис. 2).

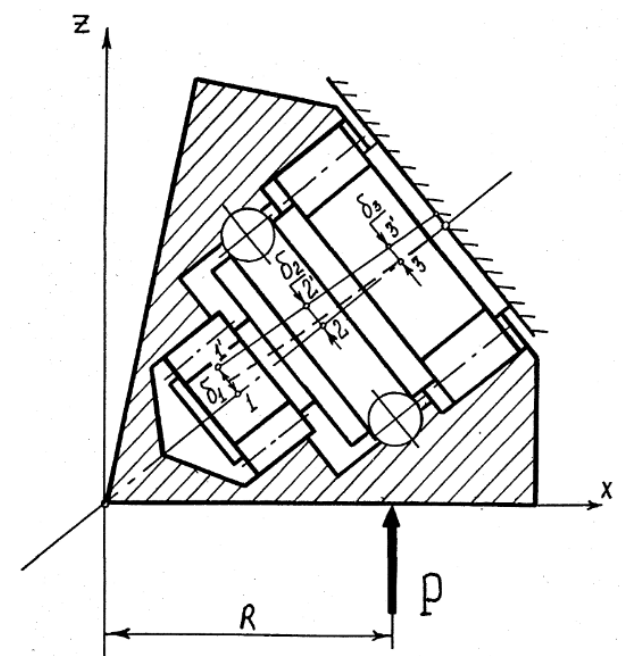

\author{
ис. 2. сиетн я схем \\ ши рошечного узл
}

рошк должн н ходиться в р вновесии под действием внешней силы $P$ и сил pe кций в подшипник х. ринято, что периферийный и концевой роликовые подшипники восприним ют только р ди льные н грузки, ш риковый з мковый подшипник - осевую и р ди льную (рис. 3).

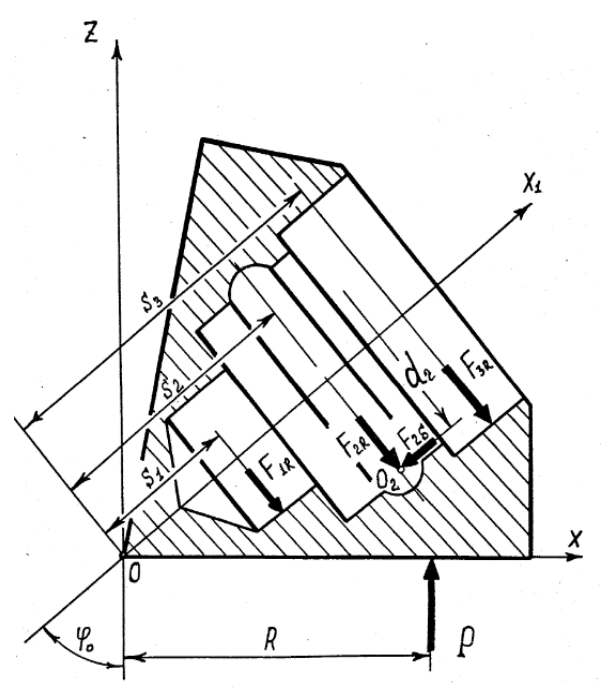

ис. 3. хем сил, действующих н и рошку 
К к к систем сил, действующих н ш рошку, является ст тически неопределимой, то для ее решения сост влены дополнительные ур внения деформ ции системы. ри этом учитыв л сь деформ ция ц пфы и конт ктные деформ ции в подшипник х. о результ т м р счетов построены 3 висимости величины ре кций в подшипник х от p диус приложения силы к ш рошке для конкретного долот 215,9 - (рис. 4). счет величины конт ктных н пряжений в подшипник х по д нной методике пок зыв ет, что н ибольшие н пряжения возник ют в ш риковом 3 мковом подшипнике. то соответствует вывод м ряд эксперимент льных исследов ний, утвержд ющих, что ш риковый подшипник р бот ет в н иболее тяжелых условиях.

ис. 4. сиетные $з$ висимости

р ди льных ре кцийв подиипник х от р диус приложения внешнего усилия $(P=10 \quad)$

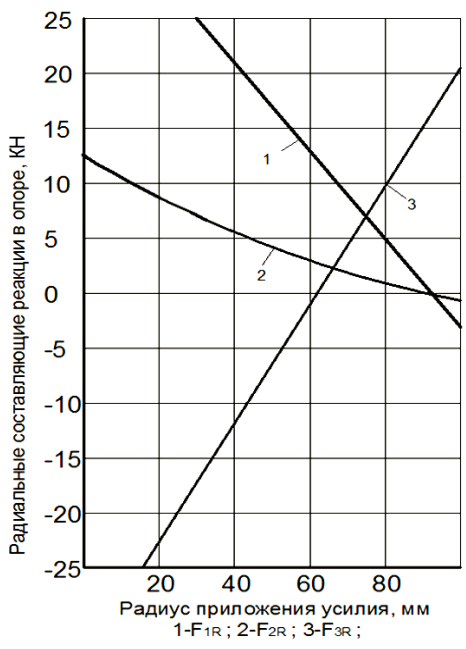

озд ние н дежной методики н литической оценки н груженности элементов долот для применения ее н пр ктике невозможно без эксперимент льного подтверждения результ тов р счетов. связи с этим предст вляют большой интерес эксперимент льные методы, применяемые для решения д нных 3 д ч.

иболее просто н грузки, действующие н зубья ш рошки долот в процессе бурения, определяются непосредственным измерением с помощью тензометрических д тчиков, н клеенных н боковые поверхности зубьев [5]. рудности 3 мер усилий в этом случ е з ключ ются в том, что зубья имеют м лые р змеры и ш рошки с н клеенными н них д тчик ми вр щ ются. езульт ты этих исследов ний пок 3 ли, что периферийный венец является более н груженным и н грузк, восприним ем я им, втрое больше, чем н вершинном венце. p боте [8] приведены результ ты эксперимент льного определения осевых усилий, действующих н зубки ш рошек с твердоспл вным вооружением. олото, опир ющееся зубк ми ш рошек н специ льные дин мометры, н груж лось осевой силой (рис. 5).

ис. 5. хем з мер

усилий н венцы

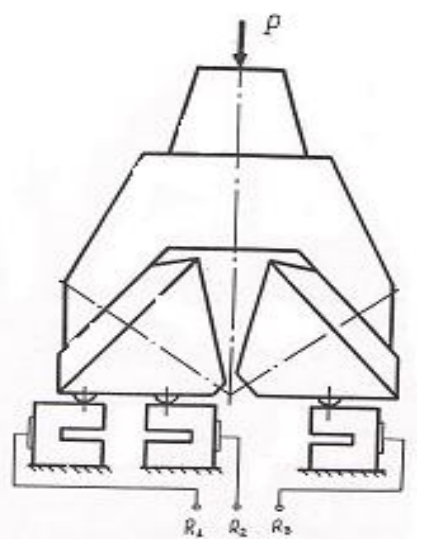


ыли исследов ны р зличные в ри нты, когд ш рошки могли опир ться н один, дв или три зубк, p сположенных н p зных венц х. о полученным результ т м трудно уст новить к кую-либо з кономерность. блюд ется тенденция к большей з груженности вершинных венцов. дн ко полученные результ ты вряд ли отр ж ют ре льную к ртину, т к к к для предотвр щения поворот при н гружении ш рошки осевой н грузкой последние прив рив лись к л п м долот . чевидно, что это дополнительное крепление ш рошек существенно изменяло жесткость конструкции, приближ я ее к стержневой системе.

нтересен метод измерения усилий, действующих н подшипники опоры ш рошки при дин мическом н гружении [16]. змерения проводились н помощью тензометрических д тчиков, н клеенных в специ льных проточк х н сменных кольц х, н ружные поверхности которых служили беговыми дорожк ми подшипников. есмотря н преимуществ прямого измерения усилий, этот метод имеет и ряд недост тков. силия измеряются в фиксиров нных точк х опорных поверхностей подшипников, в то время к к ф ктические точки приложения н грузок могут перемещ ться во время р боты долот вдоль ц пфы или смещ ться н некоторый угол от вертик льной плоскости, в которой р сположены д тчики.

опытк связ ть н груженность подшипников опор ш рошек долот с конструкцией вооружения и технологическими п р метр ми изготовления долот предст влен в p боте [17]. етодик з ключ ется в эксперимент льном определении н грузки, действующей н к ждую секцию модели ш рошечного долот во время ее р боты по 3 бою, с последующей н литической оценкой р спределения этих н грузок между подшипник ми опоры. одель долот сост влен из трех ш рошечных узлов, к ждый из которых уст новлен н цилиндрической измерительной б лке, жестко $з$ крепленной н б зовой плите (рис. 6).

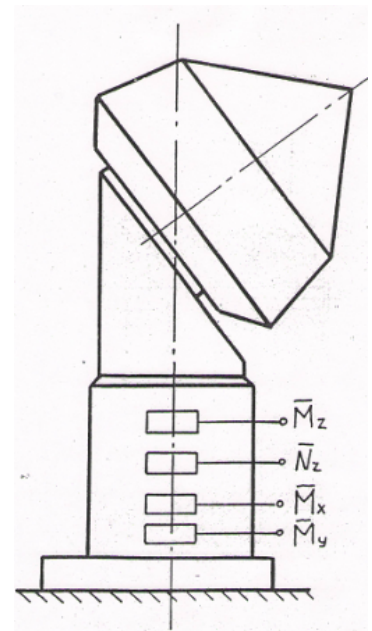

ис. 6. хем одной секции модели долот

верху н модель долот опир ется вр щ ющийся з бой. помощью смонтиров нных н 6 лке тензод тчиков определяются вертик льн я н грузк н секцию, крутящий и изгиб ющие моменты. тем с помощью гипотез и допущений производится p счет н грузок, действующих н подшипники. нн я методик позволяет определить н грузку, действующую н к ждую секцию долот, дост точно просто моделиров ть т кие погрешности изготовления долот, к к р зновысотность и р ди льное биение секций и их влияние н р спределение н грузки по секциям. достоинств м методики можно отнести и возможность проведения испыт ний н 3 бое, изготовленном из рельной горной породы.

глядн я иллюстр ция х р ктер p спределения н грузки, между подшипник ми опоры ш рошечного долот в 3 висимости от точки приложения ре кции з боя н ш рошку получен с использов нием модели ш рошечного узл , изготовленной из оптически-чувствительного м тери л [18]. рис. 7 предст влен схем приспособления для 3 крепления и н гружения модели ш рошечного узл . 
ис. 7. хем приспособления для з крепления и н гружения фотоупругой модели ш рошечного узл

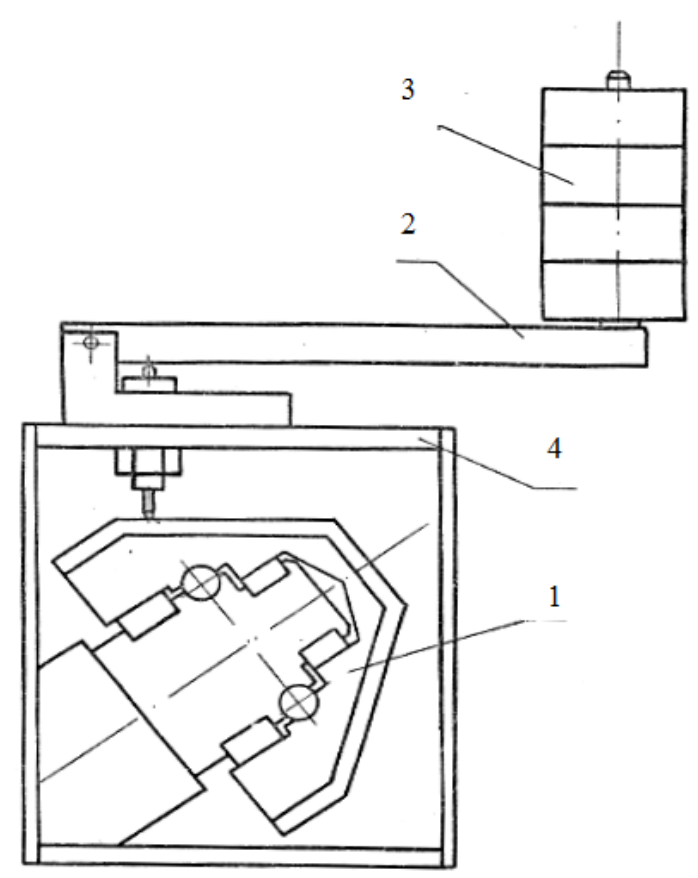

ри помещении модели в поле кругового полярископ н экр не появляется систем темных линий, н зыв емых изохром ми или полос ми. жд я полос предст вляет собой геометрическое место точек, имеющих один ковую р зность гл вных н пряжений. рис. 8 предст влен к ртин полос модели, н груженной осевой силой в 300 . трелк н рисунке пок зыв ет место приложения и н пр вление осевой силы.

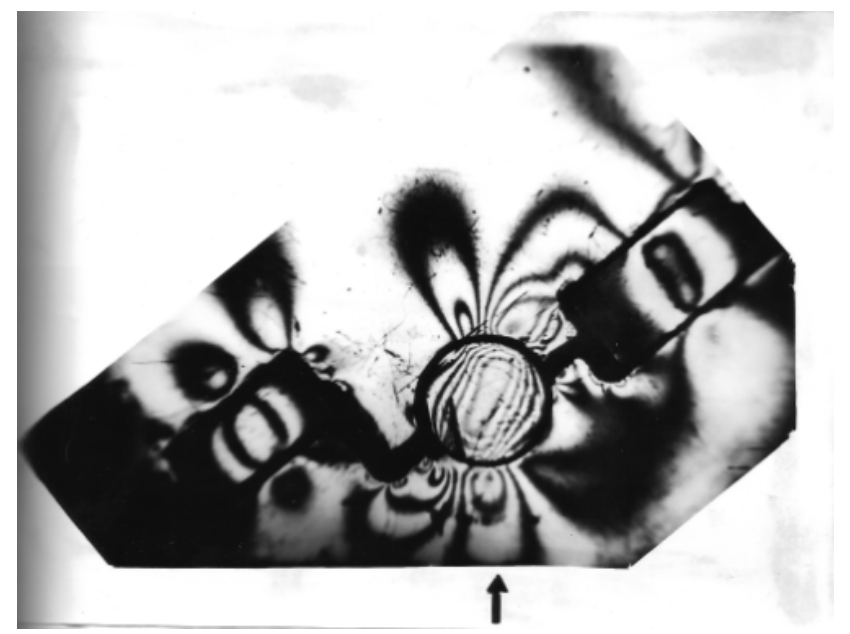

ис. 8. ртин полос модели ши рошечного узл

ля эксперимент льной оценки н груженности элементов вооружения ш рошечных долот используется т кже принцип дифференци ции з боя [19]. бой выполнен в виде трех концентрических ст льных колец. помощью гидротелескопического устройств , схем которого приведен н рис. 9, можно з мерить сумм рные осевые н грузки и крутящие моменты, действующие н одноименные венцы всех ш рошек долот , что не позволяет получить полное предст вление о р спределении н грузок по вооружению к ждой ш рошки. 


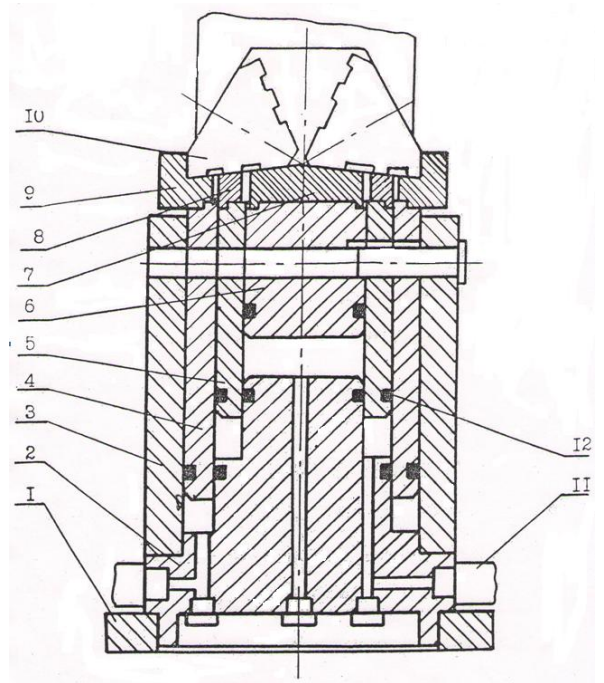

ис. 9. хемм

гидротелескопического

устройств :

1, 2, 3- дет ли корпус :

4, 5, 6- плунжеры;

7, 8, 9 - кольцевой з бой;

10 -долото; $11-$ д тчики;

12 - уплотнения

озможность р здельного определения усилий, действующих н венцы к ждой ш рошки, д ет дополнительн я дифференци ция з боя н дв сектор рительный) и нер бочий [20]. рис.10 предст влен принципи льн я схем 3 мер и регистр ции усилий вз имодействия зубьев ш рошек с з боем. ри вр щении долот по з бою ш рошки последов тельно конт ктируют с р бочим сектором з боя, угол которого выбр н т ким обр зом, что в нем может одновременно н ходиться только одн ш рошк долот.

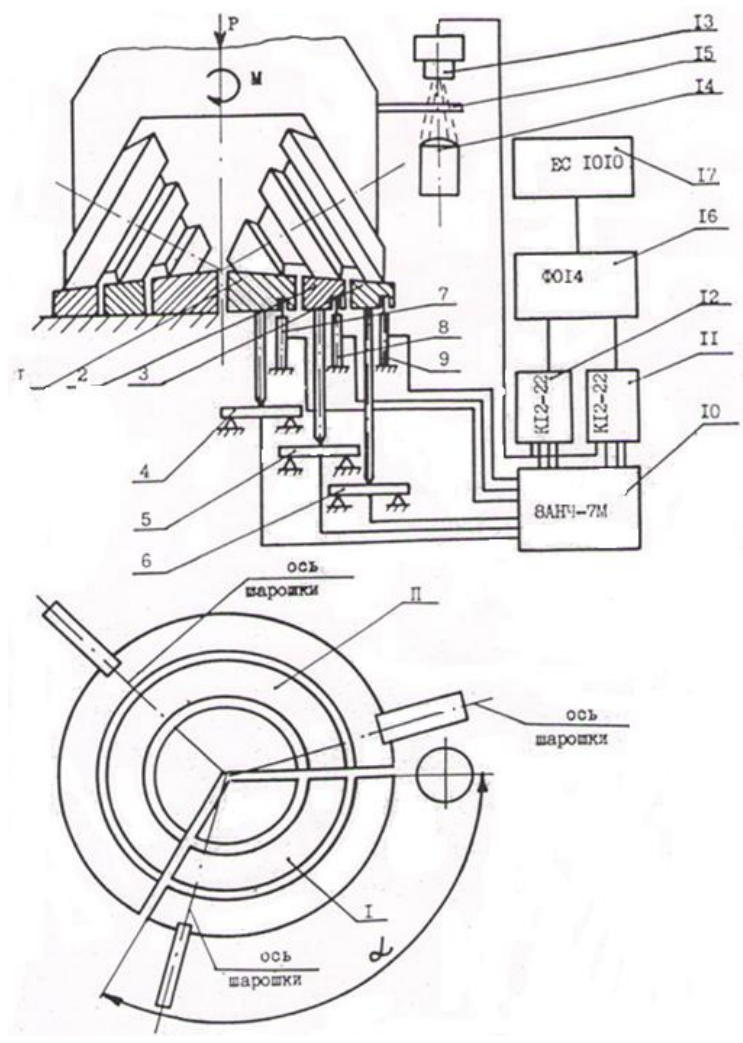

ис.10. ринципи яьн ясхем з мер и регистр циире кций вз имодействия зубьев ш рошек с з боем: 1, 2, 3-кольцевой з бой р бочего сектор ;

4, 5, 6, 7, 8,9-тензометрические б лки; 10 -усилитель; 11, 12 - осииллогр фы; 13, 14, 15- фотосчетчик; 16, 17 - преобр зов тель гр фиков 
ст льные ш рошки в это время конт ктируют с нер бочим сектором з боя, неподвижно з крепленным н корпусе измерительного устройств . нн я методик позволяет дост точно быстро и с высокой точностью оценить величины осевых и т нгенцильных усилий, действующих н к ждый венец к ждой ш рошки. езульт ты исследов ний пок з ли, что для долот тип 215,9 - н ибольшую осевую н грузку восприним ют средние венцы. езульт ты исследов ний позволяют оптимизиров ть конструкцию вооружения и опорных узлов ш рошек.

p мК ми д нного обзор ост лось еще очень большое число р бот, посвященных исследов нию н груженности вооружения и подшипников опор ш рошечных долот.

кой интерес исследов телей к д нной тем тике объясняется ее большой пр ктической зн чимостью, т к к к от эффективности р боты бурового инструмент существенно з висят технологические и экономические п р метры процесс бурения скв жин. роме того, из-з высокой сложности процессов, происходящих при р боте долот н $з$ бое, трудно выявить их основные з кономерности.

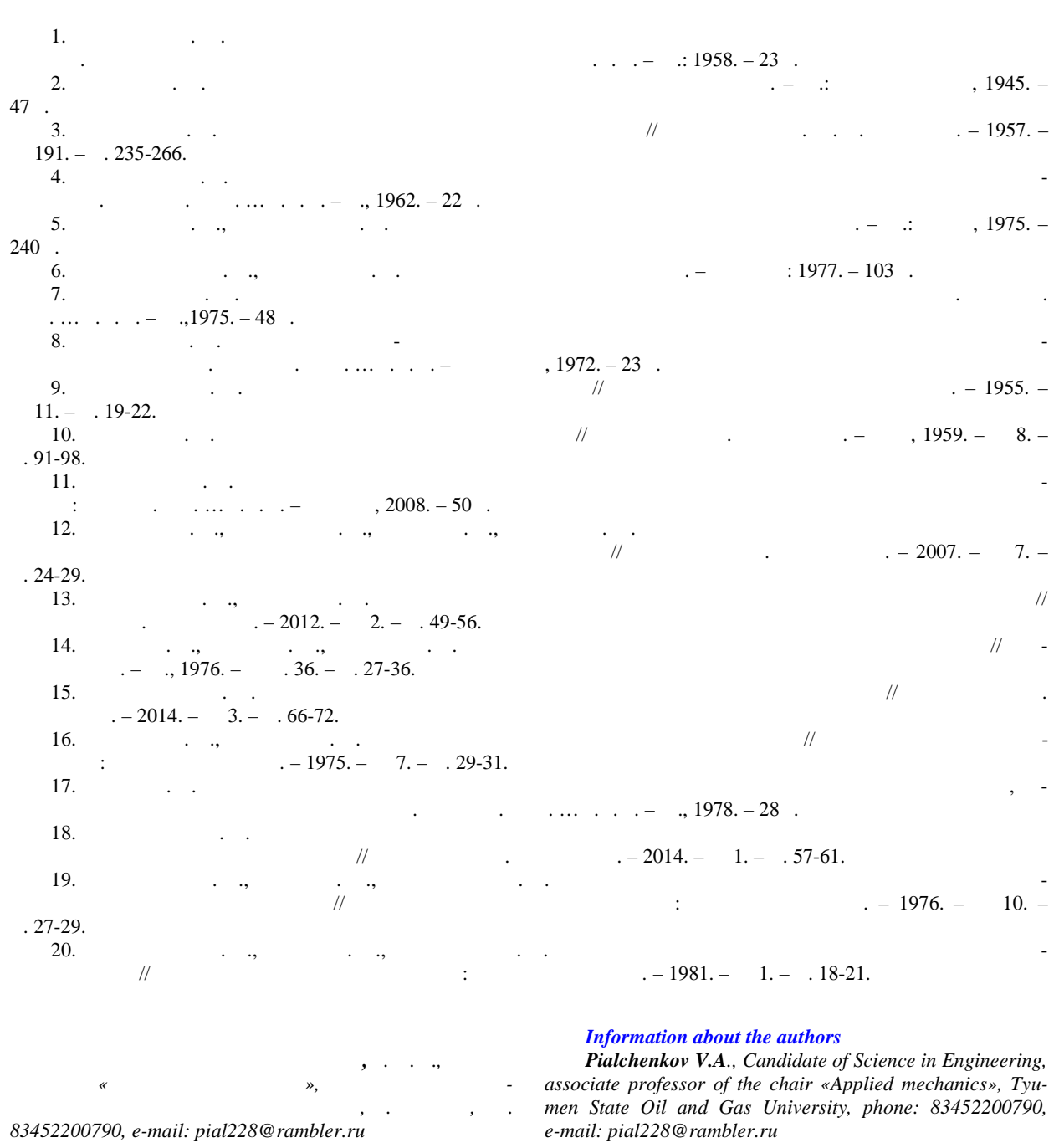

16. ост ш . ., синцев . з з зерение усилий в подшипник х опоры долот // шины и нефтяное оборудов ние: $\quad .-1975$. - № $7 .-.29-31$.

17. омм . . сследов ние влияния конструктивных и технологических ф кторов н р ботоспособность, износ и н груженность опор ш рошечных долот. втореф. дисс. ... к. т. н. - ., 1978. -28 с.

18. яльченков . . сследов ние р спределения н грузки между подшипник ми опоры ш рошечного долот с использов нием фотоупругой модели // звестия вузов. ефть и г 3. - 2014. - № 1. - . 57-61.

19. рд х ев. ., уб рх . ., оровинских . . стройство для з мер р спределения усилий и моментов по венц м ш рошечных долот // шины и нефтяное оборудов ние: . - 1976. - № 10. $.27-29$.

20. иногр дов . ., p гин яльченков . . етод исследов ния н груженности вооружения ш рошечных долот // шины и нефтяное оборудов ние: $\quad . \quad$ 1981. - № 1. - . $18-21$

ведения об вторе

яльченков л димир лексеевич, к. т. н., доцент $\kappa$ федры «рикл дня яех ник», юменский госуд рственный нефтег зовый университет, г. юмень,тел. 83452200790,e-mail: pial228@rambler.ru

Information about the authors

Pialchenkov V.A., Candidate of Science in Engineering, associate professor of the chair «Applied mechanics», Tyumen State Oil and Gas University, phone: 83452200790 e-mail:pial228@rambler.ru 